\title{
DESEMPENHO E CARACTERÍSTICAS MORFO- INTESTINAIS DE LEITOAS DESMAMADAS ALIMENTADAS COM DIETAS CONTENDO ASSOCIAÇÕES DE MANANOLIGOSSACARÍDEO
}

\author{
Saullo Diogo de Assis ${ }^{1}$, Uanderson Verríssimo de Lunaํㄹ João Garcia Caramori \\ Junior ${ }^{1}$, Gerusa da Silva Salles Correa ${ }^{1}$, André Brito Correa ${ }^{1}$, Emanuele \\ Brusamarelo ${ }^{1}$
}

1 UFMT

Correspondência: saullo.assis@svc.ifmt.edu.br

RESUMO: Avaliou-se o efeito da suplementação de mananoligossacarídeo isolado e associados com B-glucano e antibiótico em dietas de leitoas durante a fase de creche (21 aos 54 dias de idade) sobre o desempenho, características morfo- histológicas da mucosa intestinal e ocorrência de diarréia. Foram utilizadas 368 leitoas de mesma linhagem, com peso médio de $6,5 \mathrm{~kg} / \mathrm{unidade}$ experimental, distribuídas em delineamento inteiramente casualizado com quatro tratamentos: 1 Dieta controle Dieta basal - sem suplementação, 2 - Dieta basal $+1500 \mathrm{~g}$ de mananoligossacarídeo ton/ração, 3 - Dieta basal $+500 \mathrm{~g}$ de B-glucano ton/ração e 4 - Dieta basal $+250 \mathrm{~g}$ Colistina ton/ração, com quatro repetições cada e 23 animais por unidade experimental. $O$ desempenho foi avaliado pelo peso corporal, ganho de peso, consumo de ração e conversão alimentar. As características morfo-histológicas da mucosa intestinal estudadas foram altura de vilosidade, profundidade das criptas intestinais, perímetro de vilosidade e relação altura de vilosidade:profundidade de cripta do duodeno, jejuno e íleo. A ocorrência de diarréia foi observada diariamente pela avaliação da consistência das fezes. Os animais com a dieta contendo a suplementação de mananoligossacarídeo apresentaram melhora de $6,68 \%$ no ganho de peso comparada aos demais tratamentos. A utilização de MOS não apresentou diferença $(<0,05)$ na conversão alimentar. Os tratamentos não influenciaram o consumo de ração, incidência de diarreia e as características da morfo- histológicas intestinais. A suplementação de mananoligossacarídeo proporcionou os melhores resultados de ganho de peso e peso final em leitoas de linhagem comercial no período de 21 a 54 dias de idade.

Palavras-chave: aditivo; desmame; diarréia; microingredientes nutricionais; morfometria intestinal

\section{PERFORMANCE AND MORPHO-INTESTINAL CHARACTERISTICS OF WEANED GILTS FED DIETS CONTAINING COMBINATIONS WITH MANNAN OLIGOSACCHARIDES}

\begin{abstract}
In this study, we evaluated the effect of supplementing mannan oligosaccharides (MOS) solely or combined with B-glucan and an antibiotics in diets for gilts in the nursery phase (21 to 54 days of age) on the performance, morphohistological characteristics of the intestinal mucosa and occurrence of diarrhea. Three-hundred and sixty-eight gilts from the same strain, with average weight of $6.5 \mathrm{~kg} /$ experimental unit, were distributed in a completely randomized design with four treatments: 1 - Control diet (basal diet): no supplementation; 2 - Basal diet $+1,500 \mathrm{~g} \mathrm{MOS} / \mathrm{t}$ of diet; 3 - basal diet +500 B-glucan/t of diet; and 4 - Basal diet $+250 \mathrm{~g}$ colistin/t of diet, with four replicates each and 23 animals per experimental unit. The performance was evaluated through the body weight, weight gain, feed intake and feed conversion. The morphohistological characteristics of the intestinal mucosa analyzed were villus height, intestinal crypt depth, villus perimeter and villus height:crypt depth ratio of the duodenum, jejunum and ileum. The occurrence of diarrhea was observed daily by evaluating the consistency of feces. The animals on the diet containing the supplementation of MOS showed an improvement of $6.68 \%$ in weight gain compared with the other treatments. The use of MOS did not show differences $(\mathrm{P}<0.05)$ in feed conversion. The treatments did not affect feed intake, incidence of diarrhea or the morphohistological characteristics. Supplementation of mannan oligosaccharides provided the best results for weight gain and final weight in gilts of a commercial strain in the period of 21 to 54 days of age.
\end{abstract}

Key Words: additives; diarrhea; intestinal morphometry; nutritional microingredients; weaning 

com dietas contendo associações de mananoligossacarídeo

\section{INTRODUÇÃO}

Os antibióticos têm sido regularmente utilizados nas rações de suínos desde a década de 50 . Estes produtos agem na modulação da microbiota intestinal, determinando efeitos diretos e indiretos nos animais, melhorando substancialmente o ganho de peso e a eficiência alimentar principalmente na fase pós desmame (COSTA et al., 2007).

Porém, o uso de antibióticos na alimentação animal se encontra cada vez mais restrito, devido a preocupações como: o desenvolvimento de resistência das bactérias aos antibióticos empregados, queda na sua eficiência, permanência de resíduos não degradáveis nos alimentos, transmissão de bactérias resistentes ao homem através do consumo de carne e derivados, reações alérgicas em pessoas previamente sensibilizadas e toxicidade (SMITH, 1975).

Uma alternativa para reduzir o uso de antibióticos na alimentação de suínos é buscar outros aditivos que tenham efeito positivo, em especial sobre a criação de leitões, fase pela qual os animais estão mais susceptíveis a doenças e perda no desempenho.

Os prebióticos têm sido testados como eventuais substitutos, pois são ingredientes nutricionais não digeríveis que afetam beneficamente 0 hospedeiro, estimulando seletivamente o crescimento e a atividade de uma ou mais espécies de bactérias benéficas intestinais (GIBSON e ROBERFROID, 1995), dentre os prebióticos mais estudados encontram-se os mananoligossacarídeos e ß-glucanos.

Mananoligossacarídeos (MOS) e ß- glucanos são carboidratos não digeríveis, derivados da parede celular da levedura Saccharomyces cerevisiae, estes modulam a flora intestinal, reduzem a taxa de renovação da mucosa intestinal e estimulam o sistema imune (ALBINO et al., 2006), o que melhora e protege a mucosa, reduzindo lesões intestinais e propicia maior altura dos vilos e profundidade de cripta (PELICANO et al., 2005).

Estudos têm comprovado que a suplementação de prebióticos melhora o desenvolvimento de suínos (ESTRADA e DREW et al., 2001; HE e BAIDOO et al., 2002), entretanto, outras investigações reportaram pouco ou nenhum efeito dos prebióticos sobre o desempenho de leitões (HOWARD et al., 1995; MIKKELSEN et al., 2003; BUDIÑO et al., 2006).

A variação dos resultados com o uso de prebióticos na dieta de leitões pode ser atribuída à diferença entre o composto estudado, dose utilizada, condições de armazenamento, composição da dieta, estratégia de fornecimento e interação com outros aditivos presentes na dieta.

Portanto, o objetivo do presente trabalho foi avaliar o desempenho, as características morfo- histológicas da mucosa intestinal e ocorrência de diarreia de leitoas na fase de creche (21 a 54 dias de idade) em uma granja comercial, recebendo dietas que continham mananoligossacarídeos isolados, ou associados com ß-glucano e antibiótico (Colistina).

\section{MATERIAL E MÉTODOS}

Utilizou-se 368 leitoas de linhagem comercial, desmamadas aos 21 dias de idade com peso médio de $6,5 \mathrm{~kg}$, distribuídas em delineamento inteiramente casualizado com quatro tratamentos: 1 Dieta controle sem suplementação; 2 Dieta basal $+1.500 \mathrm{~g}$ de mananoligossacarídeo ton/ração; 3 Dieta basal + $500 \mathrm{~g}$ de B-glucano ton/ração; e 4 Dieta basal + $250 \mathrm{~g}$ de colistina ton/ração, quatro repetições e cada unidade experimental com 23 animais. $O$ experimento foi conduzido 
em uma granja comercial durante 33 dias na fase de creche.

Os animais foram alojados em baias metálicas suspensas, com área de $1,80 \mathrm{~m}^{2}(1,20 \mathrm{~m} \times 1,50 \mathrm{~m})$, equipadas com bebedouro do tipo chupeta e comedouros de concreto do tipo calha, a área abaixo do bebedouro era constituída de piso metálico vazado, enquanto o restante era de concreto compacto correspondendo à área adjacente aos comedouros. A temperatura, assim como a ventilação no interior da creche, foi controlada por sistema de cortina, com a finalidade de manter o conforto térmico dos animais.

As dietas experimentais (Tabela 1) foram formuladas com adaptações em relação ao nível de proteína e energia, sobre o consumo de ração para - clima da região, sendo à base de milho, farelo de soja e suplementadas com minerais e vitaminas, para atender às exigências nutricionais de suínos com alto potencial genético seguindo as recomendações de Rostagno et al. (2011), para as fases e idade: Pré I- 21은 ao $27^{\circ}$ dia de idade; Pré II- 28ㅇ ao $34^{\circ}$

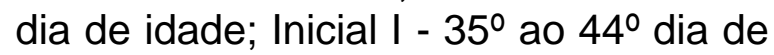
idade e Inicial II $-45^{\circ}$ ao $54^{\circ}$ dia de idade. Adicionou- se os suplementos (prebiótico e o antibiótico) nas dietas em substituição ao inerte. Os animais receberam, durante todo o período experimental (33 dias), água e ração à vontade.

Os animais foram pesados no início do período experimental e aos $27^{\circ}, 34^{\circ}, 44^{\circ}$ e $54^{\circ}$ dia de idade para determinar o peso corporal e ganho de peso (GP). O consumo de ração (CR) foi calculado considerando a quantidade de ração fornecida menos as sobras nos comedouros. A conversão alimentar (CA) foi calculada pela relação entre o consumo de ração e o ganho de peso dos animais.

Avaliou-se ocorrência de diarreia através das observações fecais das leitoas uma vez por dia, sempre às 07h30min. Considerando como presença de diarreia fezes com características físicas aquosas. A presença de fezes diarreicas no piso da baia foi utilizada como indicativo de presença de diarreia. Ao final do experimento, foi calculada a ocorrência de diarreia por unidade experimental (\%) entre 0 início e o fim do experimento.

\begin{tabular}{|c|c|c|c|c|}
\hline Ingredientes (\%) & Prél & Préll & Iniciall & Inicial || \\
\hline Milho & 25,650 & 36,050 & 47,100 & 57,785 \\
\hline Farelo de soja- 45 & 9,700 & 18,400 & 22,450 & 28,500 \\
\hline Öleo de soja & 2,000 & 2,900 & 2,800 & 2,000 \\
\hline Farinha de Carne -45 & 0,000 & 0,000 & 0,000 & 3,500 \\
\hline Açúcar Cristal & 2,500 & 2,500 & 2,500 & 5,000 \\
\hline DL- Metionina & $0, \infty 0$ & 0,000 & 0,000 & 0,148 \\
\hline L-Lisina $\mathrm{HCl}$ & 0,000 & 0,000 & 0,000 & 0,302 \\
\hline L-Treonina & 0,000 & 0,000 & 0,000 & 0,115 \\
\hline Nc Sui Pré Inicial ${ }^{12.3,4}$ & 60,000 & 40,000 & 25,000 & 2,500 \\
\hline Inerte ( Areia lavada) & 0,150 & 0,150 & 0,150 & 0,150 \\
\hline Total (\%) & 100,000 & 100,000 & 100,000 & 100,000 \\
\hline \multicolumn{5}{|l|}{ Composições calculadas } \\
\hline Energia M etabolizável (kcaVkg) & 3.450 & 3.448 & 3.451 & 3.400 \\
\hline Proteína Bruta (\%) & 18,575 & 19,743 & 19,312 & 20,173 \\
\hline Gordura Bruta (\%) & 5,603 & 6,287 & 6,527 & 5,232 \\
\hline Fibra Bruta (\%) & 1,405 & 1,922 & 2,235 & 2,668 \\
\hline Cinza (\%) & 6,219 & 6,279 & 6,107 & 4,810 \\
\hline Cálcio (\%) & $0, \circledast 54$ & 0,672 & 0,704 & 0,740 \\
\hline Fósforo Disponivel (\%) & 0,218 & 0,226 & 0,220 & 0,173 \\
\hline Lisina Total (\%) & 1,561 & 1,446 & 1,319 & 1,271 \\
\hline
\end{tabular}

Para avaliação morfo-histológica do intestino delgado utilizou-se um animal por repetição, os quais foram eutanasiados e necropsiados aos 54 dias de idade. Foram coletados dois fragmentos (A e B) por região (duodeno, jejuno e íleo) com distâncias de $15 \mathrm{~cm}$ entre os mesmos, e $5 \mathrm{~cm}$ de comprimento. As amostras foram acondicionadas em frascos contendo formol a $10 \%$ para fixação, utilizando a metodologia descrita por Nabuurs et al. (1993).As amostras foram analisadas no Laboratório de Patologia Veterinária da Universidade Federal de Mato Grosso, e lavadas em álcool $70 \%$ para a retirada do fixador, posteriormente desidratadas em série crescente de alcoóis $(80 \%$, $85 \%, 90 \%$ e $95 \%$ e duas soluções a $96 \%$ ), diafanizadas em xilol e incluídas em parafina para realização da 
Desempenho e características morfo- intestinais de leitoas desmamadas alimentadas com dietas contendo associações de mananoligossacarídeo

microtomia semiseriada a uma espessura de $5 \mu \mathrm{m}$ (Micra). Os fragmentos $A$ e $B$, correspondendo a 2 cortes histológicos de uma mesma região de cada segmento (duodeno, jejuno e íleo), foram colocados em uma mesma lâmina histológica, coradas pela hematoxilina e eosina como descrito por Behmer et al. (1976), e observados em microscópio óptico Axio Imager A2 da ZEISS.

Para estudo morfométrico da altura da vilosidade, do perímetro e das profundidades das criptas intestinais em Micra $(\mu \mathrm{m})$, as amostras foram digitalizadas e mensuradas utilizando 0 Software analisador de imagens Axio Vision 4.8.2.0 da ZEISS, acoplado a um microscópio binocular Axio Imager A2 da ZEISS. Em um total de 96 lâminas (4 tratamentos $x 4$ repetições $\times 1$ animal $x$ 3 segmentos $\times 2$ corte região), efetuando 30 leituras/lâmina (10 leituras para altura de vilo, 10 para perímetro de vilo e 10 para profundidade de cripta), perfazendo um total de 2.880 leituras de microscopia de luz ( 720 por tratamento). As medidas de altura de vilosidade (AV) foram tomadas a partir da região basal, que coincide com a porção superior das criptas, percorrendo-a longitudinalmente até seu ápice e a profundidade de criptas (PC), da sua base até a região de transição cripta-vilosidade e o perímetro (PV) contornando-se as reentrâncias presentes no vilo. A partir das medidas de AV e PC, calculou-se a relação AV/PC para cada amostra.

Os dados foram submetidos à analise estatística utilizando-se 0 programa estatístico SAEG (Sistema de Análises Estatísticas e Genéticas) versão 9.1 (SAEG, 2007) por meio dos procedimentos para análises de variância (ANOVA). Quando significativo, utilizou-se o teste Student Newman Keuls (SNK) para verificar as diferenças entre os tratamentos ao nível de a $5 \%$ de probabilidade.

\section{RESULTADOS}

No período de 21 a 27 e 21 a 34 dias de idade, não houve diferença $(p<0,05)$ no ganho de peso, consumo de ração e conversão alimentar dos animais entre as dietas experimentais (Tabela 2).

Para o período de 21 a 44 dias de idade houve diferença $(p<0,05)$ no ganho de peso dos animais que receberam dietas contendo mananoligossacarídeo em relação aos que receberam dietas com a associação de B-glucano e antibiótico, enquanto que os animais que receberam dieta controle se comportaram de forma semelhante estatisticamente àqueles que receberam suplemento de MOS na dieta.

O consumo de ração e a conversão alimentar não foram influenciados pelas dietas experimentais nessa fase.

\begin{tabular}{|c|c|c|c|c|c|}
\hline & Controle & Mananoligossacarideo & B-glucano & Antibiótico & CV\% \\
\hline \multicolumn{6}{|c|}{21 a 27 dias de idade } \\
\hline Pe so 21 dias $(\mathrm{kg})$ & 6,53 & 6,56 & 6,56 & 6,54 & - \\
\hline Peso 27 dias $(\mathrm{kg})$ & $7,91 \mathrm{~A}$ & $8,06 \mathrm{~A}$ & $8,02 \mathrm{~A}$ & $7,88 \mathrm{~A}$ & 2,48 \\
\hline GP (kg) & $1,38 \mathrm{~A}$ & $1,49 \mathrm{~A}$ & $1,45 \mathrm{~A}$ & $1,34 \mathrm{~A}$ & 12,74 \\
\hline CR (kg) & $1,59 \mathrm{~A}$ & $1,68 \mathrm{~A}$ & $1,61 \mathrm{~A}$ & $1,66 \mathrm{~A}$ & 4,41 \\
\hline $\mathrm{CA}(\mathrm{kg} / \mathrm{kg})$ & $1,15 \mathrm{~A}$ & $1,12 \mathrm{~A}$ & $1,11 \mathrm{~A}$ & $1,27 \mathrm{~A}$ & 12,86 \\
\hline \multicolumn{6}{|c|}{21 á 34 dias de idade } \\
\hline Peso 34 dias $(\mathrm{kg})$ & $10,27 \mathrm{~A}$ & $10,49 \mathrm{~A}$ & $10,35 \mathrm{~A}$ & $10,46 \mathrm{~A}$ & 2,50 \\
\hline $\mathrm{GP}(\mathrm{kg})$ & $3,74 \mathrm{~A}$ & $3,93 \mathrm{~A}$ & $3,79 \mathrm{~A}$ & $3,92 A$ & 6,21 \\
\hline CR $(\mathrm{kg})$ & $4,36 \mathrm{~A}$ & $4,55 \mathrm{~A}$ & $4,44 \mathrm{~A}$ & $4,52 \mathrm{~A}$ & 4,16 \\
\hline $\mathrm{CA}(\mathrm{kg} / \mathrm{kg})$ & $1,16 \mathrm{~A}$ & $1,16 \mathrm{~A}$ & $1,17 \mathrm{~A}$ & $1,15 \mathrm{~A}$ & 4,22 \\
\hline \multicolumn{6}{|c|}{21 a 44 dias de idade } \\
\hline Peso 44 dias $(\mathrm{kg})$ & $14,43 \mathrm{AB}$ & $14,75 \mathrm{~A}$ & $14,17 \mathrm{~B}$ & $14,04 \mathrm{~B}$ & 1,81 \\
\hline GP (kg) & $7,79 A B$ & $8,19 \mathrm{~A}$ & $7,61 \mathrm{~B}$ & $7,50 \mathrm{~B}$ & 3,36 \\
\hline CR (kg) & $10,64 \mathrm{~A}$ & $11,03 \mathrm{~A}$ & $10,64 \mathrm{~A}$ & $10,57 \mathrm{~A}$ & 2,81 \\
\hline $\mathrm{CA}(\mathrm{kg} / \mathrm{kg})$ & $1,34 \mathrm{~A}$ & $1,34 \mathrm{~A}$ & $1,39 \mathrm{~A}$ & $1,41 \mathrm{~A}$ & 3,15 \\
\hline \multicolumn{6}{|c|}{ 21 a 54 dias de idade } \\
\hline Peso 54 dias $(\mathrm{kg})$ & $19,99 \mathrm{~B}$ & $20,96 \mathrm{~A}$ & $19,77 \mathrm{~B}$ & $19,28 \mathrm{~B}$ & 2,62 \\
\hline GP (kg) & $13,46 \mathrm{~B}$ & $14,40 \mathrm{~A}$ & $13,21 \mathrm{~B}$ & $12,74 \mathrm{~B}$ & 3,92 \\
\hline CR (kg) & $25,71 \mathrm{~A}$ & $26,54 \mathrm{~A}$ & $25,44 \mathrm{~A}$ & $25,81 \mathrm{~A}$ & 3,17 \\
\hline $\mathrm{CA}(\mathrm{kg} / \mathrm{kg})$ & $1,91 \mathrm{AB}$ & $1,84 \mathrm{~A}$ & $1,92 \mathrm{AB}$ & $2,02 \mathrm{~B}$ & 3,43 \\
\hline \multicolumn{6}{|c|}{$\begin{array}{l}\text { Médias seguidas de mesma letra na linha não diferem estatisticamente pelo teste SNK, ao } \\
\text { nivel de } 5 \% \text { de probabilidade. }\end{array}$} \\
\hline & & tratam & tos & & c \\
\hline
\end{tabular}
apresentaram efeito $(p<0,05)$ sobre a incidência de diarreia durante o período avaliado (Tabela 3). 
Tabela 3 - Incidência de diarréia no período de 21 aos 54 dias de idade.

\begin{tabular}{ll}
\hline Tratamento & Frequência (\%) \\
\hline Controle & $37,88 \mathrm{~A}$ \\
Mananoligossacarídeo & $39,39 \mathrm{~A}$ \\
B-glucano & $43,18 \mathrm{~A}$ \\
Antibiótico & $29,54 \mathrm{~A}$
\end{tabular}

Médias seguidas de mesma letra maiúscula na coluna não diferem entre si estatisticamente pelo teste SNK, ao nivel de $5 \%$ de probabilidade.

Nas análises morfo- histológicas do intestino delgado (Tabela 4), não foram observados diferenças $(p<0,05)$ para as variáveis alturas de vilosidades $(\mathrm{AV})$, profundidade de criptas (PC), perímetro de vilosidades (PV) e sobre a relação altura da vilosidade/profundidade de cripta (AV/PC) nos diferentes seguimentos estudados (duodeno, jejuno e íleo).

\begin{tabular}{|c|c|c|c|c|}
\hline \multicolumn{5}{|c|}{ Duodeno } \\
\hline Tratamento & AV & $\mathrm{PC}$ & $\mathrm{PV}$ & AVIPC \\
\hline Controle & $337,09^{3}$ & $395,41^{a}$ & $745,17^{2}$ & $0,91^{2}$ \\
\hline Mananoligossacarídeo & $309,01^{\mathrm{a}}$ & $41281^{\mathrm{a}}$ & $680,12^{2}$ & $0,79^{2}$ \\
\hline B-glucano & $334,76^{2}$ & $434,68^{2}$ & $714,86^{2}$ & $0,84^{2}$ \\
\hline Antibiótico & $325,80^{\mathrm{a}}$ & $454,74^{\mathrm{a}}$ & $712,51^{2}$ & $0,74^{2}$ \\
\hline CV\% & 14,07 & 16,62 & 17,04 & 19,95 \\
\hline \multicolumn{5}{|c|}{ Jejuno } \\
\hline Tratamento & AV & $\overline{P C}$ & PV & AVIPC \\
\hline Controle & $305,27^{2}$ & $651,94^{2}$ & $323,81^{2}$ & $1,01^{2}$ \\
\hline Mananoligossacarídeo & $305,61^{2}$ & $659,57^{2}$ & $323,01^{\mathrm{a}}$ & $1,00^{2}$ \\
\hline B-glucano & $266,62^{2}$ & $611,95^{2}$ & $343,14^{2}$ & $0,82^{\mathrm{a}}$ \\
\hline Antibiótico & $273,94^{2}$ & $624,14^{2}$ & $329,21^{\mathrm{a}}$ & $0,89^{2}$ \\
\hline CV \% & 17,18 & 19,07 & 13,76 & 17,83 \\
\hline \multicolumn{5}{|c|}{ ileo } \\
\hline Tratamento & AV & $\mathrm{PC}$ & $\mathrm{PV}$ & AVIPC \\
\hline Controle & $297,02^{\mathrm{a}}$ & $628,41^{3}$ & $318,43^{2}$ & $1,00^{2}$ \\
\hline Mananoligossacarídeo & $269,31^{\mathrm{a}}$ & $554,23^{\mathrm{a}}$ & $278,03^{2}$ & $1,04^{2}$ \\
\hline B-glucano & $267,18^{2}$ & $578,57^{2}$ & $276,47^{2}$ & $1,09^{2}$ \\
\hline Antibiótico & $236,77^{\mathrm{a}}$ & $517,41^{\mathrm{a}}$ & $270,33^{2}$ & $0,96^{2}$ \\
\hline CV \% & 19,36 & 17,57 & 15,36 & 15,67 \\
\hline
\end{tabular}

\section{DISCUSSÃO}

No período de 21 a 54 dias de idade, os animais alimentados com dieta contendo suplementação de mananoligossacarídeo demonstraram melhora de 6,98\% no ganho de peso diferindo daqueles mantidos com dieta associadas a ß-glucanos, antibiótico e dieta controle, os quais não diferiram entre si.

Observou-se que os resultados de desempenho obtidos pelos animais alimentados com dietas contendo a suplementação de mananoligossacarídeos apresentaram maior peso e ganho de peso principalmente na fase final, quando comparados aos animais que receberam as dietas controle e associadas.

Estes resultados estão de acordo com Corassa et al. (2012), que ao investigarem os efeitos de dietas com mananoligossacarídeo, ácidos orgânicos, probióticos e antibióticos sobre o desempenho de leitões de 21 a 49 dias de idade encontraram que os animais que receberam dietas sem aditivos apresentaram pior conversão alimentar e os que receberam dietas suplementadas com mananoligossacarídeos, acidificante e probiótico demonstraram desempenho semelhante àqueles com antimicrobianos. Assim, avaliando diferentes níveis de $\beta$-glucano $(60,120$, $180,240 \mathrm{~g} /$ ton) na dieta de leitões dos 21 aos 60 dias de idade, Mendes et al. (2010), encontraram efeito linear positivo com melhora de $3,2 \%$ e $4,7 \%$ para o ganho de peso e peso diário dos leitões.

Cabe ressaltar que a suplementação do MOS influenciou positivamente os resultados de desempenho em comparação aos demais tratamentos se mostrando como uma opção para substituição dos antibióticos da dieta, buscando atender às exigências estabelecidas pelos países importadores da carne suína.

Esses resultados diferem dos encontrados por Sanches et al. (2006), que ao estudarem probiótico (à base de Bacillus subtillis) $150 \mathrm{~g}$ ton/ração, $1000 \mathrm{~g}$ ton/ração prebiótico (Mananoligossacarídeo), simbiótico $1150 \mathrm{~g}$ ton/ração e um controle positivo antibiótico $60 \mathrm{~g}$ ton/ração (Olaquindox) sobre 0 desempenho de leitões desmamados; e também por Hahn et al. (2006), ao utilizarem diferentes níveis de 
Desempenho e características morfo- intestinais de leitoas desmamadas alimentadas com dietas contendo associações de mananoligossacarídeo

B-glucano $(0,01$ à $0,04 \%)$ e antibiótico (Apramicina) na dieta de leitões, não encontraram efeito significativo para 0 ganho de peso, consumo de ração e conversão alimentar.

Para o consumo de ração não houve diferença $(p<0,05)$ nos diferentes períodos estudados. Resultados semelhantes quanto a administração de microingredientes na dieta de leitões na fase de creche, também tem sido relatados por Utiyama et al. (2006) que avaliaram os efeitos dos antimicrobianos $(0,5 \mathrm{~g} / \mathrm{kg}$ de bacitracina de zinco + $0,5 \mathrm{~g} / \mathrm{kg}$ de olaquindox), dos prebióticos $(30 \mathrm{~g}$ de mananoligossacarídeo), probióticos (Bacillus subtilis e Bacillus lincheniformis) e $0,5 \mathrm{~g}$ de extrato vegetal (alho, cravo, canela, pimenta, tomilho, cinamaldeido e eugenol) e não encontraram diferença no consumo de ração para a fase estudada. Os resultados encontrados podem estar atribuídos segundo Junqueira et al. (2009), entre outros fatores, à composição dos aditivos utilizados e ao desafio imunológico a que os animais foram submetidos.

Nos períodos de 21 a 27, 21 a 34 e 21 a 44 dias de idade, os resultados de conversão alimentar não diferiram $(p<0,05)$ entre os tratamentos. Entretanto de 21 a 54 dias de idade verificou-se efeito significativo entre os tratamentos com a adição de prebióticos e a associação com B-glucano estes apresentaram melhora de 5,44; 8,91 e $4,95 \%$ respectivamente, em relação ao tratamento com a suplementação de antibióticos.

Analisando todo 0 período experimental de 21 a 54 dias de idade os animais a suplementação do MOS proporcionou melhor resultado de conversão alimentar, ou seja, os animais que receberam dietas com o prebióticos foram mais eficientes na transformação do alimento em ganho de peso quando comparados com àqueles que receberam dietas com MOS associado. Dessa forma os níveis de utilização de MOS nas dietas devem ser cada dia mais estudados na busca de diminuir o uso de antibióticos.

Os tratamentos não influenciaram a incidência de diarreia, como nos achados de Santos et al. (2010), Braz et al. (2011) e Corassa et al. (2012) que não encontraram efeito de mananoligossacarídeo, probióticos, acidificantes e antimicrobianos sobre a frequência de diarreia. Corroborando com esses resultados Budiño et al. (2010), ao estudarem diferentes níveis de frutoligossacarídeo $(0,0 ; 0,2 ; 0,4$ e $0,6 \%$ ), e por Silva et al. (2006), ao pesquisarem o probiótico Pediococcus acidilactici associado ou não ao Bacillus subtilis. Esses pesquisadores também não verificaram efeitos destes produtos sobre a incidência de diarréia.

$\mathrm{Na}$ literatura os resultados ainda são muito controversos em relação a esta variável $e$ isto se deve às diferenças encontradas nos tipos de probiótico e prebiótico utilizados, dosagem, condições sanitárias (desafio) e ambientais presentes nos experimentos.

Os resultados encontrados neste estudo para as análises morfohistológicas do intestino delgado não indicaram nenhuma melhora quanto à integridade do epitélio intestinal nos segmentos estudados, pela adição dos microingredientes.

Diferentemente do que ocorreu para desempenho a suplementação de MOS na dieta e sua associação com Bglucano e Colistina não influenciou a morfo- histologia do intestino delgado, segundo Albino et al.,(2006) o MOS têm como função melhorar e proteger a mucosa, reduzindo as lesões intestinais e propiciando maior altura dos vilos e da profundidade de cripta, melhorando a digestibilidade e 0 teor da energia metabolizável das rações, pois propicia o desenvolvimento da flora intestinal, 
porém isso não ocorreu, o que pode estar associado à quantidade de administração do MOS na dieta, bem como o tempo de fornecimento destes, em especial para a categoria estudada neste trabalho.

As vilosidades desempenham importante papel no processo de absorção de nutrientes no intestino delgado, sendo que o aumento desta estrutura proporciona maior superfície de contato e, como consequência, pode haver aumento na absorção dos nutrientes no lúmen intestinal (GARTNER e HIATT, 2001). Pequenos incrementos são fundamentais para manutenção da integridade da mucosa intestinal, uma vez que determinam a dimensão da superfície de contato do intestino e, consequentemente, a capacidade digestiva e absortiva do segmento (BOLELI et al., 2002).

Trabalhando com $0,2 \%$ de MOS nas rações de leitões desmamados, Castillo et al. (2008) também não encontraram diferenças em AV, PC e AV/PC no duodeno e jejuno dos animais em comparação aos animais alimentados com dieta contendo zinco na forma orgânica ou dieta controle, sem a adição de qualquer moderador de crescimento.

Ao estudarem o uso de probiótico (Saccharomyces cerevisiae) e prebiótico (MOS) sobre a altura de vilosidades do duodeno de suínos aos 120 dias de idade Chiquieri et al. (2006) também não verificaram efeito da adição destes microingredientes. Esses resultados não satisfazem as expectativas de que 0 consumo de probiótico e/ou prebiótico na ração melhora a qualidade da mucosa intestinal.

Avaliando 0 efeito de extratos vegetais e antimicrobianos sobre a morfometria intestinal de leitões aos 56 dias de idade, Oetting et al. (2006), não observaram efeito dos aditivos sobre a profundidade de cripta e altura de vilosidades do duodeno e do jejuno. Da mesma forma, Biagi et al. (2006) não notaram efeito dos níveis $(0,3,6$ e 12 ppm) de gluconato de sódio sobre a profundidade de cripta e altura de vilosidade do jejuno, íleo e ceco de suínos aos 70 dias de idade.

Ao avaliarem diferentes níveis de ácido benzoico (0;0,25; 0,50 e 0,75\%) e um tratamento testemunha com ácido fumárico na dieta de leitões de 28 aos 53 dias de idade, Gheler et al. (2009), observaram maior altura de vilosidades e profundidade de criptas, independente do nível utilizado.

Comparando a adição de $100 \mathrm{~g}$ do antibiótico (á base de avilamicina), probiótico (á base de Bacillus toyoi) $1500 \mathrm{~g}$ ton/ração, prebiótico (à base de oligossacarídeo) $500 \mathrm{~g}$ ton/ração e glucanato de sódio (contendo 98\% de gluconato de sódio) $250 \mathrm{~g}$ ton/ração na dieta de suínos no período de 28 aos 142 dias de idade, Junqueira et al. (2009), não observaram diferença para altura de vilosidade e profundidade de cripta do duodeno e jejuno.

A relação altura de vilosidade:profundidade de cripta $(\mathrm{AV}: \mathrm{PC})$ não apresentou diferenças $(p<0,05)$ entre os tratamentos. Esta variável é um parâmetro importante de ser observada, uma vez que a mesma está diretamente relacionada com a maior capacidade de absorção de nutrientes, que pode ser afetada pela menor altura de vilosidades em decorrência do aumento na taxa de descamação epitelial resultante do incremento da profundidade da cripta, visando assegurar a adequada taxa de renovação celular e garantir a reposição das perdas de células da região apical das vilosidades (ARAÚJO et al., 2006; OETTING et al., 2006). Desta forma, pode-se inferir que quanto maior a relação $A V: P C$ melhor a capacidade de absorção de nutrientes e menores são as perdas energéticas com a renovação celular. 
Desempenho e características morfo- intestinais de leitoas desmamadas alimentadas com dietas contendo associações de mananoligossacarídeo

No entanto isto não ocorreu nesse experimento quando se compara os dados de morfometria intestinal com os dados de desempenho. Os animais não apresentaram diferenças na relação AV:PC; porém maior desempenho foi encontrado nos animais que receberam dietas com a suplementação de MOS.

O fato dos animais suplementados com mananoligossacarídeo terem apresentado diferenças significativas no desempenho, em comparação aos que receberam dietas de MOS associados a antibiótico e B-glucano, demonstrou ser viável a utilização desse microingrediente para evitar a utilização de antibióticos, mantendo- se o mesmo padrão de desempenho animal e atendendo as exigências do mercado internacional.

\section{CONCLUSÃO}

A adição de mananoligossacarídeo nas dietas proporciona melhores resultados de ganho de peso e peso final em leitoas de linhagem comercial no período de 21 a 54 dias de idade.

Mananoligossacarídeos, associados a ß-glucano e antibióticos não influenciam a incidência de diarreia e características morfo- intestinais de leitoas com idade de 21 a 54 dias em condições de desafio sanitário.

A utilização de microingredientes alternativos é viável para evitar a utilização de antibióticos, mantendo- se o mesmo padrão de desempenho animal e atendendo as exigências do mercado internacional.

\section{REFERÊNCIAS}

ALBINO, L.F.T. et al. Uso de prebióticos à base de mananoligossacarídeo em rações para frangos de corte. Revista Brasileira de Zootecnia, v.35, n.3, p.742-749, 2006.

ARAÚJO, L. F.; JUNQUEIRA, O. M.; LOPES, E. L. et al. Utilização da levedura desidratada (Saccharomyces cerevisiae) para leitões na fase inicial. Santa Maria, Ciência Rural, v.36, n.5, set/out., p.1576-1581, 2006.

BEHMER, O. A.; TOLOSA, E. M. C.; FREITAS NETO, A. G. (Eds.). Manual de técnicas para histologia normal e patológica. São Paulo: Edart, 1976. 256p.

BIAGI, G.; PIVA, A.; MOSCHINI, M. et al. Effect of gluconic acid on piglet growth performance, intestinal microflora, and intestinal wall morphology. Journal of Animal Science, v.84, p.370-378, 2006.

BOLELI, I.C. et al. Estrutura funcional do trato digestório. In: MACARI, M. et al. Fisiologia aviária aplicada a frangos de corte.

Jaboticabal: FUNEP/UNESP, 2002. p.75-95.

BRAZ, D.B., COSTA, L.B., BERENCHTEIN, B., TSE, M.L.P. et al.; Acidificantes como alternativa aos antimicrobianos promotores do crescimento de leitões. Archivo de Zootecnia, v.60, p.745756, 2011.

BRITO, J.M., FERREIRA, A.H.C.; probióticos, prebióticos e simbióticos na alimentação de nãoruminantes. Revista Eletrônica Nutritime, v.11, n.1, p.3070 - 3084, 2014.

BUDIÑO, F. E. L.; THOMAZ, M. C.; KRONKA, R. N. Efeito da adição de probiótico e/ou prebiótico em dietas de leitões desmamados sobre o desempenho, incidência de diarréia e contagem de coliformes totais. Brazilian Journal of Veterinary Research and Animal Science, São Paulo, v.43, Suplemento, p.59-67, 2006.

CASTILLO, M.; MARTÍN-ORÚE, S.M.; TAYLORPICKARD, J.A.; Use of mannan-

oligosaccharides and zinc chelate as growth promoters and diarrhea preventative in weaning pigs: effects on microbiota and gut function. Journal of Animal Science, v.86, p.94-101, 2008.

CHIQUIERI, J.M.S., SOARES, R.T.R.N., SOUZA, J.C.D. et al.; Probiótico y prebiótico en la alimentación de cerdos en crecimiento y terminación. Archivo de Zootecnia, v.55, p.305-308, 2006.

CORASSA, A.; LOPES, D.C.;BELLAVER, C; Mananoligossacarídeos, ácidos orgânicos e probióticos para leitões de 21 a 49 dias de idade. Archivo Zootecnia, v.61, n.235, p.467476, 2012. 
ESTRADA, A.; DREW, M.D.; KELSSEL,A. Van. Effect of the dietary supplementation of fructooligosaccharides and Bifidobacterium longum to early-weaned pigs on performance ande fecal bacterial populations. Canadian Journal of Animal Science, v.81, p.141- 148, 2001.

GARTNER, L.P.; HIATT, J.L. Color textbook of histology. 2.ed. Baltimore: Saunders, 2001. 592p.

GHELER,T.R.;ARAÚJO, L.F.; SILVA, C.C.;Uso de ácido benzoico na dieta de leitões. Revista Brasileira Zootecnia, v.38, n.11, p.2182-2187, 2009.

GIBSON, G.R., ROBERFROID, M.D. Dietary modulation of the human colonic microbiota: introducing the concept of prebiotics. Journal of Nutrition, v. 125, n.6, p.1401-1, 1995.

HAHN, T.W.; LOHAKARE, J.D.; LEE, S.L. et al. Effects of supplementatation of $\beta$-glucans on growth performance, nutrient digestibility and immunity weanling pigs. Journal of Animal Science, v.84, p.1422-1428, 2006.

HE, G.; BAIDOO, S.K.; YANG, Q. et al. Evaluation of chicory inulin extracts as feed additive for early-weaned pigs. Journal of Animal Science, v.80, S1, p.81-91, 2002.

HUAYNATE, R. R. A.; THOMAZ, M. C.; KRONKA, R. N. et al. Uso de probióticos em dietas de suínos: incidência de diarréia, desempenho zootécnico e digestibilidade de rações. Brazilian Journal of Veterinary Research and Animal Science, v.43, n.5, p.664 $-673,2006$.

JUNQUEIRA, O. M; GARIBALDI, L. C; BARBOSA, S;. Uso de aditivos em rações para suínos nas fases de creche, crescimento e terminação. Revista Brasileira Zootecnia, v.38, n.12, p.2394-2400, 2009.

MENDES, C. B. S.; FONTES, D. O.; GUEDES, R. M. C. Suplementação de betaglucano a dietas de leitões de 21 a 60 dias de idade. Arquivo Brasileiro de Medicina Veterinária e Zootecnia, v.62, p.696-705, 2010.

NABUURS, M. J. A. et al. Villus height and crypt depth in weaned and unweaned pigs, reared under various circumstances in the Netherlands. Research in Veterinary Science, v.55, p.78-84, 1993.
OETTING, L. L.; UTIYAMA, C. E.; GIANI, P.A. et al. Efeitos de extratos vegetais e antimicrobianos sobre a digestibilidade aparente, morfometria e histologia intestinal de leitões recém desmamados. Viçosa, Revista Brasileira de Zootecnia, v.35, n.4, p.13891397, 2006.

PELICANO, E.R.L. et al. Intestinal mucosa development in broiler chickens fed natural growth promoters. Revista Brasileira de Ciência Avícola, v.7, n.4, p.221-229, 2005.

ROSTAGNO, H. S.; ALBINO, L. F. T.; DONZELE, J. L. et al. Composição de alimentos e exigências nutricionais. Tabelas brasileiras para aves e suínos. 3. ed. Viçosa: Editora UFV, 2011.

SAEG - Sistema para Análises Estatísticas, Versão 9.1. Fundação Arthur Bernardes - UFVViçosa, 2007.

SANCHES, A. L.; LIMA, J, A, F.; FIALHO, E. T. et al. Utilização de probiótico, prebiótico e simbiótico em rações de leitões ao desmame. Ciência e Agrotecnologia, v.30, n.4, p.774777, 2006.

SANTOS, V.M.;THOMAS,M.C.;PASCOAL,L.A.F. et al.; Digestibilidade, desempenho e características morfofisiológicas do trato digestorio de leitões desmamados sob dietas com mananoligossacarídeo. Pesquisa

Agropecuária Brasileira, Brasília, v.45, n.1, p.99-105, 2010.

SILVA, C. A.; HOSHI, E. H.; PACHECO, G. D. et al. Avaliação de probióticos (Pediococcus acidilactici e Bacillus subtilis) após o desmame e efeitos no desempenho dos leitões. Semina: Ciências Agrárias, v.27, n.1, p.133-140, 2006.

SMITH, H. W. Clinical problems of preventive medicine. World's Poultry Science Journal, Mt. Morris, v.31, n.2, p.104-15, 1975.

UTIYAMA, C.E.; OETTING, L.L.; GIANI, P.A. et al. Efeitos de antimicrobianos, prebióticos, probióticos e extratos vegetais sobre a microbiota intestinal, a freqüência de diarréia e o desempenho de leitões recém-desmamados. Revista Brasileira de Zootecnia, v.35, n.6, p.2359-2367, 2006. 